\title{
Enhancing early engagement with mental health services by young people
}

This article was published in the following Dove Press journal:

Psychology Research and Behavior Management

25 November 2014

Number of times this article has been viewed

\section{Jane Burns \\ Emma Birrell \\ Young and Well Cooperative Research Centre, Abbotsford, VIC, Australia}

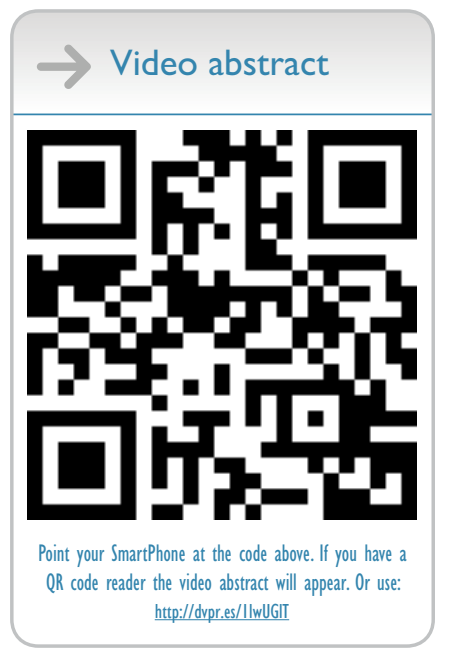

Correspondence: Jane Burns Young and Well Cooperative Research Centre, Unit 17, 7I Victoria Crescent, Abbotsford, VIC, Australia

Tel +6I 39937 I 333

Fax +6I 394164416

Email jane@yawcrc.org.au
Abstract: International studies have shown that the prevalence of mental illness, and the fundamental contribution it make to the overall disease burden, is greatest in children and young people. Despite this high burden, adolescents and young adults are the least likely population group to seek help or to access professional care for mental health problems. This issue is particularly problematic given that untreated, or poorly treated, mental disorders are associated with both short- and long-term functional impairment, including poorer education and employment opportunities, potential comorbidity, including drug and alcohol problems, and a greater risk for antisocial behavior, including violence and aggression. This cycle of poor mental health creates a significant burden for the young person, their family and friends, and society as a whole. Australia is enviably positioned to substantially enhance the well-being of young people, to improve their engagement with mental health services, and - ultimately - to improve mental health. High prevalence but potentially debilitating disorders, such as depression and anxiety, are targeted by the specialized youth mental health service, headspace: the National Youth Mental Health Foundation and a series of Early Psychosis Prevention and Intervention Centres, will provide early intervention specialist services for low prevalence, complex illnesses. Online services, such as ReachOut.com by Inspire Foundation, Youthbeyondblue, Kids Helpline, and Lifeline Australia, and evidence-based online interventions, such as MoodGYM, are also freely available, yet a major challenge still exists in ensuring that young people receive effective evidence-based care at the right time. This article describes Australian innovation in shaping a comprehensive youth mental health system, which is informed by an evidence-based approach, dedicated advocacy and, critically, the inclusion of young people in service design, development, and ongoing evaluation to ensure that services can be continuously improved.

Keywords: young people, mental health, technology, participation, well-being, help-seeking

\section{Introduction}

Globally, mental health is recognized as being integral to the ability of a person to reach his or her potential, cope with the burdens of everyday life, and contribute to society at large. ${ }^{1}$ It has been predicted that by 2030, depression will carry the highest disease burden in high-income countries. ${ }^{2}$ Many mental health problems - including high prevalence disorders like depression, anxiety, drug and alcohol use, and the subsequent repercussions of this, suicidal ideation, self-harm, and suicide - increase significantly in adolescence and young adulthood. ${ }^{3}$ The stigma attached to mental illness continues to serve as a barrier to seeking assistance, ${ }^{4,5}$ translating to people not receiving timely, appropriate help and care. The utilization of the Internet as a source of information for health issues, including mental health concerns continues to escalate, ${ }^{6-10}$ clearly demonstrating 
the role the online space can play in the provision of support and care for those enduring mental illness.

In Australia, in the late 1990s, two fundamental reports were published that have shaped our mental health reform efforts and ensured the involvement of young people in service reform; for the purpose of this paper, a young person is defined as someone aged 12-25 years old.

The first report, known as the Burdekin Report, captured stories from 1,276 people, ranging from young people to the elderly, about their personal experience of living with a mental illness. Produced by the Australian Human Rights and Equal Opportunity Commission, this national inquiry focused on the potential to enhance positive human rights and included: "rights to access to health care, rights to decent housing and an adequate standard of living, and adequate representation and protection in the criminal justice system." 11

Many of the rights outlined in the Burdekin report are consistent with the social determinants theory outlined by the World Health Organization (WHO) in its approach to mental health promotion and prevention. Fundamentally, the approach moved beyond a disease-focused model to one that encompassed individual and societal issues collectively, with a focus on well-being. For the purpose of this review, we use the WHO definition of well-being: "a state in which every individual realises his or her own potential, can cope with the normal stresses of life, can work productively and fruitfully, and is able to make a contribution to her or his community." 12

The second report, known as the Keys Young Report, provided a voice for 89 young people aged 12-24, who participated in the indepth interviews. The report specifically invited them to provide feedback on both their formal and informal experience of help seeking and their access to care. This report was the first to ask young people about their attitudes and knowledge about mental illness. ${ }^{13}$

Since the publication of both the Burdekin and the Keys Young reports, mental health reform efforts have been structured around the US Institute of Medicine framework, which supports a holistic approach, targeting both modifiable risk and protective factors across multiple settings. It argues for an integration of efforts that includes a focus on promotion, prevention, early intervention, and treatment and relapse prevention. This approach fully acknowledges that to address complex youth mental health problems, every population segment - including our most vulnerable - must be targeted to promote the well-being of all individuals in society. ${ }^{14,15}$
Increasingly, it is acknowledged that - while we have made significant advances in some areas of scientific inquiry in relation to the mental health and well-being of young people - the mental health sector faces significant systemic policy challenges. First and foremost, despite significant reform efforts and continued government investment, mental health care in Australia only receives $7.7 \%$ of the federal budget, while carrying $13 \%$ of the overall health burden. ${ }^{16} \mathrm{~A}$ secondary but important concern, and as acknowledged by WHO, is the fact that well-being, mental health, and mental illnesses - and their debilitating effects - have been dismissed by society and neglected by governments. As a result, a large gap exists between the burden of mental health problems and the available resources and services required to address this significant social and economic problem. ${ }^{17}$

\section{Importance of mental health promotion for young people}

While one in four young people experiences a mental illness, ${ }^{18}$ the delay between the first early warning signs and symptoms and access to effective treatments can span 15 years. In Australia, engaging young people with the services available is a challenge; only $13 \%$ of young men and $31 \%$ of young women seek professional assistance. ${ }^{19}$ To prevent the escalation of mental health problems and to address ongoing risks (such as self-medication), ${ }^{20}$ appropriate diagnosis and effective intervention must occur. Mental health problems, if they are not properly addressed, can deteriorate, impacting significantly on the quality of a young person's life and their prospects for the future.

Evidence, ranging from the clinical and epidemiological through to personal stories of distress and burden, clearly suggests that mental health and behavioral problems are major causes of disability and impairment for young people. Major depression is one of the top four causes of years lost to disability. The highest-ranking top 25 causes of disability include anxiety disorders, drug and alcohol problems, schizophrenia, and bipolar effect disorders. By age 5, mental health and behavioral problems become an important and soon dominant cause of years lost to disability, peaking between ages $20-29 .^{21}$

\section{Young people are not seeking help for mental health problems}

Traditionally, a medical model in health care assumes that the family doctor will provide an evidence-based treatment for the specific illness. In youth mental health, this approach fails, generally because young people do not seek help when 
they are experiencing symptoms that suggest they have a mental health problem. In an effort to ensure that young people access quality care at the right time, it is critical that we understand what young people think about mental health and the attitudes they may have towards potential treatment options.

Over the last decade, significant data have been collected from nationally representative populations of young people to better understand knowledge, stigma, help-seeking, and what approaches to early intervention and treatment might be effective. This paper draws on three examples. The first of these data were collected via two community samples of people aged 18-90 years in 2002 and 2004-2005. Interviews were conducted over the telephone with 2,003 people participating in the 2002 survey; 3,200 people participated in the 2004-2005 study. From this broad population sample, 285 and 400 people, respectively, were aged between 18-25 years. ${ }^{22}$ Young people were asked to think about general health and mental health problems, including depression. They were also asked to think about their knowledge and understanding of the prevalence of depression, what age they thought depression and anxiety might begin, and their preferences for specific types of treatment. The findings from this study clearly demonstrated a lack of recognition of depression as a major general health issue; however, it is the most frequently named mental health problem. Although knowledge about depression was good, young people preferred to seek help from family or friends $(61 \%-65 \%)$ and to use nonpharmacological treatments. One-quarter of the young people surveyed believed antidepressant medications were harmful and that alcohol use may be helpful. These attitudes present a challenge to the mental health sector in engaging young people early to receive treatment for mental health problems. ${ }^{23}$

A second study was published using data collected from two clinical audits of selected Australian general practices $(\mathrm{N}=5,236,1998-1999 ; \mathrm{N}=370,2000-2002)$ to better understand the first-hand experience of young people aged 16-25 years who had accessed care. ${ }^{22}$ It is very common for young people to present to general practitioners with a mental health concern; however, only one-half of these young people were formally diagnosed with a mental health condition or received professional treatment. The most commonly reported interventions were nonpharmacological alone, or in combination with pharmacological treatments. Despite the belief that young people are overdiagnosed and overmedicated, only rarely is pharmacological treatment alone provided. The major message taken from this study is the clear need to further encourage the development of a collaborative and holistic model of care, rooted in the wide availability of information, treatment, and effective e-health services. It was also argued that a priority be placed on increasing accessibility to specific psychological treatments.

A third study relating to challenges in mental health service delivery found that young people were using the Internet to search for guidance as to how to help themselves with their own mental health issues, with $21 \%$ of $12-17$ year olds and $34 \%$ of $18-25$ year olds reporting they had searched online for support. Factors that were found to influence use of the Internet included being female and using the Internet after $11 \mathrm{pm} .{ }^{24}$ Young people also reported that they were happy with the information provided via the Internet with $55 \%$ of $12-17$ year olds and $45 \%$ of $18-25$ year olds surveyed, agreeing that it provided them with the assistance they required. ${ }^{24}$ Over three-quarters of the $12-25$ year olds surveyed felt that the Internet had helped a little or a lot with a mental health, alcohol, or other substance use problem, and that $85 \%$ of young people surveyed would recommend it to a friend or family member. In addition, 94\% felt somewhat satisfied or very satisfied with the information provided online. The study illustrated that a general Internet search served as the primary gateway to access information about mental health and well-being, but once this initial search phase was complete, peer support groups and forums proved less popular than mental health and generalist websites. The survey respondents were less in favor of online journals, reading other people's stories, or accessing fact sheets, but general information and question-and-answer forums were popular. ${ }^{24}$ The paper argued that young people are using technologies to access information and assistance in relation to mental health concerns and that technologies could, therefore, provide an important adjunct to support traditional forms of clinical engagement and/or act as a support platform enabling professionals to interact via the Internet. ${ }^{24}$ It was also argued that different types of technologies, such as mobile apps, could be used to communicate and encourage interactive participation between the young person and the service or clinician.

\section{Online environment as a critical new setting for mental health service provision for young people}

The Internet has become an integral part of the everyday lives of young people. With the rapid proliferation of social networking and a growing realization that relationships are often formed and maintained online, it is increasingly 
acknowledged that the concept of online versus offline is completely outdated. The way in which young people use and engage with technologies has substantially shifted with the introduction of smart devices, faster Internet speeds, and improved accessibility. Therefore, the acknowledgment of the Internet as a setting is increasingly acceptable and the importance of it as a virtual environment in which young people spend time, interact, and engage with peers and others becomes more relevant in the context of mental health reform. ${ }^{24}$ In particular, it gives young people voice; empowered consumers can create their own digital content and share it both rapidly and prolifically via social networking websites, such as Facebook and Twitter.

Barriers to traditional care, such as stigma and geographical isolation, taken with the cost and complexity of federal and state funding models, contrive to create a mental health system that is challenging to navigate. ${ }^{25}$ Given the prolific use of the Internet by young people, ${ }^{8}$ technologies are increasingly being used to deliver mental health interventions. Indeed, research over the last decade clearly shows that the Internet provides a space where young people feel in control, giving them the confidence to discuss complex and delicate issues, ${ }^{24,26}$ including depression, ${ }^{24}$ sexuality and sexually transmitted diseases, ${ }^{27}$ physical activity, and nutrition. ${ }^{28}$ When included in an integrated system of care, online interventions and clinical services provided over the Internet can potentially offer greater reach with the capacity to provide an anonymous gateway to care, which is available 24 hours a day, 7 days a week, while also potentially reducing the costs for service providers. ${ }^{29}$ Most importantly, young people report feeling comfortable accessing online information about mental health issues, thereby engaging young people who may not otherwise seek assistance and avoid the traditional pathways to care and help. ${ }^{30}$

Academic studies looking at social trends and connections have illustrated consistently that social networking services are "associated with increased social capital and reduced loneliness." 31 Both are known to protect against the development of mental illness. Traditional hurdles to social interaction are flattened by online communication platforms, rendering geographical location irrelevant, allowing young people from marginalized groups to engage and participate, free from conventional barriers. For example, a young person with a disability can be a part of a community from the comfort of their bedroom at the click of a mouse. Widespread Internet access serves as the ideal platform to "rapidly engage young people," 32 with the possibility of forming genuine connections through already existing online communities.
Social networking services and online gaming have created new ways for people to interact and support one another, creating an accessible and safe environment for isolated members of the community. ${ }^{8}$

Young people are using technologies to access information and assistance in relation to mental health concerns, which provide a potential alternative to traditional forms of clinical engagement, enabling professionals to interact via the Internet. ${ }^{24}$ This style of service design, which truly puts the young individual accessing the online resource in control, allows for mental health issues to be tackled privately and at their own pace. This was highlighted in a US study, where research showed that those Internet users who have a stigmatized mental illness, such as depression or anxiety, were more likely to connect to information and assistance via online means, in contrast to Internet users who were not afflicted with these stigmatized conditions. ${ }^{33}$

The level of information and communication technology literacy is very high among young people, ${ }^{8}$ who are using various forms to socially interact with their family and friends, access entertainment, and as a space to learn. Online interventions are demonstrating positive results in the treatment and management of mental health conditions, ${ }^{34}$ encouraging further research as to how to make these services more effective and widely known. Furthermore, online services have been shown to increase mental health literacy, ${ }^{35}$ potentially altering help-seeking behaviors in the face-to-face context; mental health literacy is closely linked to seeking appropriate professional assistance and treatment. ${ }^{36}$

\section{Value of youth participation in mental health landscape Background}

The importance of youth participation and the role that it must play in creating personcentric mental health and well-being services that meet the needs of young people is emerging as a critical element in creating engaging and relevant services. As a strategy to improve social inclusion, community connectedness, and intergenerational dialogue, models of youth participation are being embraced by government and the not-for-profit sector alike. ${ }^{37}$

For the purpose of this paper, the authors have adopted the definition of youth participation as expressed by Farthing in 2012; "a process where young people, as active citizens, take part in, express views on, and have decision-making power about issues that affect them." ${ }^{38}$

Within this definition, there is an inherent link between consultation and follow through, which includes actually 
embracing the ideas of young people and putting these views into action. Youth participation is built on a "strong and respectful relationship" with young people, ${ }^{39}$ with genuine regard for the opinions of the end-users in the sector. Organizations must invest in the implementation of their youth participation program, ensuring it is meaningfully integrated within their organizational structure. This includes not only consultation with young people, but rather truly embedding young people in the decision-making processes that effect change at both an operational and organizational level. ${ }^{39}$

\section{Need for youth participation}

Youth participation has been noted as playing a particularly effective role in health promotion, and a vital element to the success of health promotion programs in addressing and enhancing protective factors known to benefit mental health. ${ }^{40-42}$ This is brought into stark focus when considering that mental health difficulties are a challenge unmatched by any other health issue for those under the age of 25. Figures consistently tell a discouraging story of suicide as the leading cause of death for $15-24$ year olds, ${ }^{43}$ with $25 \%$ of that age group experiencing symptoms of mental health difficulty each year. ${ }^{19}$ When considering the urgent need to remedy this situation, it is imperative to consider the concept of well-being as a part of mental health and to examine the risk and protective factors that comprise a person's overall mental health. ${ }^{44}$

Taking youth participation in this setting, evidence shows that social inclusion - a cornerstone of mental health, centering on engagement with people in community, group and personal relationships - has participation at its core. ${ }^{40,45-47}$ These types of social networks can mitigate risk factors for mental ill-health, by providing a sense of belonging and connectedness. ${ }^{46-50}$ Policies and services that enhance social inclusion are becoming more rapidly favored by modern organizations and, as such, youth participation models, which indeed embody the notion of social inclusion, are becoming more attractive. ${ }^{51-54}$

There is scope to explore the role of youth participation as it directly relates to the promotion of mental health and well-being. While a light has been shone on the policy and context of youth participation ${ }^{54-56}$ and young people's experiences of the model, ${ }^{57-59}$ existing diverse approaches ${ }^{52-54}$ could be examined to interrogate why youth participation is becoming recognized as best practice. Existing evidence shows that in certain settings youth participation can improve services, rendering them more adaptable, supportive, and accessible. ${ }^{60}$
Organizations involving young people in decision-making have also reported making "more accurate, relevant decisions which are better informed and hence more likely to be implemented." 61

While there is growing evidence about the rationale for the involvement of young people in decision-making processes, there remains a dearth of research into the method and impact of this model. ${ }^{62}$

\section{Research exploring participation and its role in promoting mental health and well-being for young people}

Emerging research is beginning to paint a picture of the important role of youth participation in promoting the mental health and well-being of young people, and while the importance of youth participation for health promotion is well-argued in the literature, ${ }^{45}$ some fundamental areas of research in this area to date remain largely unexplored.

Existing research provides some insight into levels of youth participation and the potential barriers that might affect the engagement of young people. For example, a large cross-sectional survey of 2,542 young people in southern Australia undertaken by Baum et al (2000) investigated social, community, and political participation and the impact of socioeconomic status, health, and other demographics on levels of participation. This particular study did not provide any additional insights into the role of participation and its impact on mental health and well-being. ${ }^{45}$

Likewise, Berry et al (2007) found that increased levels of participation in particular activities of randomly selected participants from a New South Wales coastal town in Australia correlated with lower levels of psychological distress. ${ }^{63,64}$ Both of the findings presented whet our appetite for a deeper understanding of the role of youth participation in the promotion of mental health and well-being.

This exploration can begin with a broadening of the definition of youth participation, beyond the traditional political and social constructs, which were favored in the two studies acknowledged above. While it is noted that there is diversity in participation, there is also an argument made by Vromen (2003) that a value can be placed on certain types of participation above other types of participation ${ }^{65}$ and that future research must recognize new forms of participation, such as online activities. ${ }^{65}$

This has certainly been an area of interest to Australian researchers who have used qualitative methods to examine the conceptualization of participation by young people themselves, including the scope and meaning of the activities in 
which young people engage. While this work has delivered some new insights into the meaning young people attach to activities and social relationships, there is scarce evidence tying this back to a greater understanding of the role of participation in the promotion of mental health and well-being, though resilience and steering the development of more engaging, youth-friendly mental health services have been suggested as positive impacts..$^{24,55,66,67}$

There is also an important consideration for new research in this area to encompass a plurality of voices, not just the views of one group. By extension, it is important to include the experiences of all stakeholders (eg, professionals, academics, policy makers) in the youth participation model, not only the young people themselves, ${ }^{53,68}$ although it must be noted that young people are integral members of communities and should be considered such in any examination of impact of participation.

A further area for research into participation must examine the specific setting in which the participation takes place. Young people around the world were found to preference participation that allowed them to connect the multidimensions of their lives (social, cultural, and economic), gave them agency to do so flexibly, and through a process of building their own networks. ${ }^{69}$ Taking the multidimensional approach even further, Collin's (2009) indepth international study noted the nexus of a suitable environment (eg, the Internet or particular organizations) and opportunities to make a difference by connecting to foster meaningful relationships, and enabling positive personal development. ${ }^{52,56,69}$ To view this insight through the prism of mental health and well-being, it is imperative that new research explores both the participation of young people and the setting in which mental health services could be delivered.

Finally, new research into participation must advance the current literature by examining the three spheres in which youth participation can occur, no longer looking at each of these in a vacuum, ie, only the experience of the individual, ${ }^{45,56,57,64,65}$ the experience of a policy, program or organization, or the experience of a community. It is the intersection of these three inextricably linked spheres - through exploring experiences, benefits, and challenges - that may provide the greatest insights into the impact of youth participation and the role it may play in the promotion of mental health and well-being.

\section{Examples of youth-friendly services and the importance of youth participation ReachOut.com by Inspire Foundation}

ReachOut.com by Inspire Foundation is a mental health promotion and prevention service that provides information, support, and resources to help develop resilience, increase coping skills and self-efficacy, facilitate help-seeking behavior, and improve young people's understanding of mental health issues. ${ }^{66,70}$ While earlier research, and indeed an ongoing dialogue points to the negative social outcomes of online participation, increasingly, research is showing that community involvement and social interaction are increased by Internet use - with these benefits translating to the offline lives of young people. ${ }^{71}$ ReachOut.com by Inspire Foundation, the first online mental health support service to be launched in Australia, ignited the dialogue surrounding the provision of online care and support. ${ }^{66}$ Technologically driven interventions can help encourage the accessing of face-to-face services, "allowing young people who need intensive services to readily access them whilst also supporting the large number of young people with mild or moderate mental health concerns." 72

ReachOut.com by Inspire Foundation's commitment to their youth involvement agenda is exemplified in the role of their youth ambassadors. These volunteers are central to the organization and have been integral to the development of new programs and strategies since its inception in $1998 .{ }^{73}$ The programs offered by ReachOut.com by Inspire Foundation have been found to support young people to become "service ready," 35 reinforcing that this online space is one young people can rely on when they are facing troubles with their mental health and well-being. Developed and maintained in partnership with young people, ReachOut.com has been shown to effectively engage young people in mental health promotion and prevention material. ${ }^{74}$

\section{headspace and eheadspace.org.au}

Founded in 2006, headspace is Australia's youth mental health foundation. headspace is a community-based health service, providing care and advice to young people aged 12-25 years old. headspace centers offer a broad range of services, encompassing mental and physical health, education, employment, and substance misuse. ${ }^{75}$ headspace has an extensive youth participation program, (headspace Youth National Reference Group), comprised of young people from the headspace center's youth reference groups around the country. This holistic approach to well-being aims to provide a space that is comfortable, accessible, and welcoming for young people. ${ }^{8}$ At the core of headspace is the principle of being youth-friendly and creating spaces for young people that are frequently absent from the traditional models of primary care or specialist mental health care services. ${ }^{75}$ 
As well as serving as a hub for these interdisciplinary services, headspace aims to increase help-seeking behaviors in the community. ${ }^{76}$ headspace centers focus on early and preventive interventions, with the aim of targeting symptoms prior to the development of more serious mental health conditions. The physical presence of these hubs in the community aid in the establishment of a local dialogue; centers frequently engage with local sports clubs, schools, universities, and private businesses to enhance educational opportunities and fundraising. This priority of bolstering the knowledge of youth mental health is a key factor and central to the headspace model; this recognition and destigmatization of a mental health service further enhances the accessibility of the headspace services and generates a safe and attractive environment for young people to approach. For young people to access the services offered by headspace, they need to know about them, ${ }^{77}$ making the community outreach and wider relationship vital to the model's success.

Early evaluations indicate positive outcomes in relation to patient recovery. A 2009 survey indicated that almost all respondents reported their mental health improving since their visit to headspace, with this finding being reinforced by the respondents also reporting "decreased symptoms, increased confidence, and changed emotions and behaviors." ${ }^{.76}$ In addition, these services have been proven to attract young people who are at much higher risk of suicide or self-harm in comparison to the general population. ${ }^{78}$ In response to increasing demand and young people's preferences, headspace, in 2010, also established an interactive online counseling service, eheadspace, providing an "online gateway for young people to access help." ${ }^{\prime}$ An evaluation of the eheadspace service and model is currently underway.

\section{Orygen Youth Health, Platform}

Young people face numerous barriers in accessing care, and a significant remedy to these barriers is the provision of youth-friendly services. ${ }^{68}$ While consulting young people about a service for young people themselves might seem logical, evidence is also emerging that providing young people with an opportunity to share their insights actually contributes to the establishment of a more efficient, accessible system for themselves and their peers. ${ }^{68}$ Orygen Youth Health (OYH) is a mental health service in Melbourne, Australia, designed exclusively to support young people. Founded and established in 2001 with the partnership of the University of Melbourne, Melbourne Health, and the Colonial Foundation, ${ }^{79}$ OYH continues to serve as an example of quality youth mental health care with a strong evidence base to support Early Psychosis Prevention and Intervention Centres. ${ }^{32,80,81}$

Consumer participation is being increasingly recognized as an essential component in the development, implementation, and evaluation of mental health services. ${ }^{82}$ This model firmly adheres to the definition of youth participation as outlined earlier in the paper, highlighting the importance of end-user feedback and responding to their critiques. OYH embraces a model that greatly encourages a dialogue between past and present clients, sharing their experiences to be able to help others. ${ }^{68}$ With this mindset, the Platform team was created. There are a number of examples as to how young people can become actively engaged in the programs offered via Platform; giving feedback to the OYH staff on what has worked for you as an individual in relation to treatment, serving as a participant on an internal project committee, assisting with research projects, and writing for the external newsletter, to name some. ${ }^{83}$

Platform meets monthly at the OYH Parkville Campus in Melbourne to encourage interaction and sharing of experiences. ${ }^{84}$ The youth participation program at $\mathrm{OYH}$ is overseen by a youth participation coordinator, ensuring that the wider service is meaningfully connected to the young people contributing to the development of the organization. ${ }^{82}$ Furthermore, from Platform, the Peer Support program was developed; this branch is comprised of ex-OYH clients who volunteer their time to support the recovery process of existing clients in both the inpatient and outpatient settings. ${ }^{80}$

\section{Conclusion}

This paper has aimed to demonstrate the current innovative approaches to the provision of mental health information, care and treatment, and justify the case for future investment and research in the role of meaningful youth participation and the growth of online support platforms.

Significant financial investment and service reform has been made in the youth mental health sector in Australia, but figures regarding service utilization by young people have failed to drastically alter, with one study suggesting $80 \%$ of young people are failing to seek help for mental health difficulties. ${ }^{18}$ Fundamentally, Australia has the key ingredients to an integrated system of care that promotes engagement with both online (ie, ReachOut.com by Inspire Foundation and eheadspace.org.au) and offline services (ie, headspace and the OYH Research Centres) across promotion, prevention, early intervention, and treatment. With the rollout of high-speed broadband increasing the capacity and speed of connections across the country, the Internet will 
continue to expand in its reach and capabilities, ${ }^{24}$ thereby, providing a model environment for the expansion of online mental health-related services for young people, and the enhancement of existing youth mental health services.

Online-based organizations like ReachOut.com by Inspire Foundation are connecting with young people who are experiencing psychological distress who may not access any other kinds of professional support and care. ${ }^{85}$ While this type of engagement is important in promotion and prevention activities for an integrated system of youth mental health care, to be truly effective, online supports must also facilitate the first steps and encouragement to support helpseeking and access to early intervention services; increasing the interconnection between young people and mental health services is a crucial step. ${ }^{86}$

The existing models of youth participation provide insight into what it is possible to achieve by establishing an authentic relationship between organizations and the young people they are funded to serve. Youth participation programs promote an inclusive environment, ${ }^{37}$ encouraging the end-users to contribute to the creation of services and policies that will be accessed by them and/or their peers - this approach builds trust and rapport.

Young people bear a disproportionate weight of the disease burden of mental illness, ${ }^{80}$ and traditional primary health pathways are failing to adequately care for those needing help. By embarking on an approach that sees technology and youth participation included in an integrated system of care ${ }^{8}$ is a logical step and one that Australia - through significant cooperation and innovation - is leading the world in.

\section{Disclosure}

Associate Professor Jane Burns is founder and chief executive officer of the Young and Well Cooperative Research Centre and is a principal research fellow at the Orygen National Centre of Excellence in Youth Mental Health, University of Melbourne, Australia. She also serves as a director of the Cooperative Research Centres Association. Emma Birrell is the research officer at Young and Well Cooperative Research Centre.

\section{References}

1. World Health Organization. Mental Health Action Plan 2013-2020. Geneva: World Health Organization; 2013.

2. World Health Organization. Global Burden of Mental Disorders and the Need for a Comprehensive, Coordinated Response from Health and Social Sectors at the Country Level. Report by the Secretariat. Geneva: World Health Organization; 2011.

3. Harrington R, Rutter M, Fombonne E. Developmental pathways in depression: Multiple meanings, antecedents, and endpoints. Dev Psychopathol. 1996;8(4):601-616.
4. Patel V, Flisher AJ, Hetrick S, McGorry P. Mental health of young people: a global public-health challenge. Lancet. 2007;369(9569):1302-1313.

5. Horgan A, Sweeney J. Young students' use of the Internet for mental health information and support. $J$ Psychiatr Ment Health Nurs. 2010;17(2):117-123.

6. Ybarra ML, Suman M. Help seeking behavior and the Internet: a national survey. Int J Med Inform. 2006;75(1):29-41.

7. Ybarra ML, Eaton WW. Internet-based mental health interventions. Ment Health Serv Res. 2005;7(2):75-87.

8. Burns JM, Davenport TA, Christensen H. Game on: Exploring the Impact of Technologies on Young Men's Mental Health and Wellbeing Findings from the First Young and Well National Survey. Melbourne, Australia: The Young and Well Cooperative Research Centre; 2013.

9. Griffiths KM, Christensen H. Internet-based mental health programs: a powerful tool in the rural medical kit. Aust J Rural Health. 2007; 15(2):81-87.

10. Griffiths KM, Farrer L, Christensen H. The efficacy of internet interventions for depression and anxiety disorders: a review of randomised controlled trials. Med J Aust. 2010;192(Suppl 11):S4-S11.

11. National Inquiry Concerning the Human Rights of People with Mental Illness (Australia); Burdekin B, Hall D, Guilfoyle M. Human Rights and Mental Illness: Report of the National Inquiry into the Human Rights of People with Mental Illness. Canberra: Australian Government Publishing Service; 1993.

12. World Health Organization. Mental health: a state of well-being [webpage on the Internet]. Geneva: World Health Organization; 2013. Available from: http://www.who.int/features/factfiles/mental_health/ en/. Accessed May 15, 2014.

13. Keys Young Australia. Research and Consultation Among Young People on Mental Health Issues: Final Report. Canberra, Australia: Keys Young Australia; 1997. Available from: http://www.health.gov.au/internet/ main/publishing.nsf/Content/623B53634177BF00CA257BF000209 AEA/\$File/reconsall.pdf. Accessed April 28, 2014.

14. Mrazek PJ, Haggerty RJ. Reducing Risks for Mental Disorders: Frontiers for Preventive Intervention Research. Washington, DC, USA: National Academies Press; 1994.

15. O'Connell ME, Boat T, Warner KE, editors. Preventing Mental, Emotional, and Behavioral Disorders Among Young People: Progress and Possibilities. Washington DC, USA: National Academies Press; 2009.

16. Hickie IB, McGorry PD, Davenport TA, et al. Getting mental health reform back on track: a leadership challenge for the new Australian Government. Med J Aust. 2014;200(8):445-448.

17. World Health Organization. Promoting Mental Health. Concepts, Emerging Evidence, Practice. Summary Report. Geneva: World Health Organization; 2004. Available from: http://apps.who.int/iris/ bitstream/10665/42940/1/9241591595.pdf?ua=1. Accessed April 28, 2014.

18. Burgess PM, Pirkis JE, Slade TN, Johnston AK, Meadows GN, Gunn JM. Service use for mental health problems: findings from the 2007 National Survey of Mental Health and Wellbeing. Aust $N Z J$ Psychiatry. 2009;43(7):615-623.

19. Slade T, Johnston A, Teesson M, et al. The Mental Health of Australians 2: Report on the 2007 National Survey of Mental Health and Wellbeing. Canberra, Australia: Commonwealth of Australia Department of Health; 2009.

20. Kendall PC, Kessler RC. The impact of childhood psychopathology interventions on subsequent substance abuse: policy implications, comments, and recommendations. J Consult Clin Psychol. 2002;70(6): 1303-1306.

21. Monshat K, Khong B, Hassed C, et al. "A conscious control over life and my emotions:" mindfulness practice and healthy young people. A qualitative study. J Adolesc Health. 2013;52(5):572-577.

22. Hickie IB, Luscombe GM, Davenport TA, Burns JM, Highet NJ. Perspectives of young people on depression: awareness, experiences, attitudes and treatment preferences. Early Interv Psychiatry. 2007;1(4):333-339. 
23. Hickie IB, Fogarty AS, Davenport TA, Luscombe GM, Burns J. Responding to experiences of young people with common mental health problems attending Australian general practice. Med $J$ Aust. 2007;187(Suppl 7):S47-S52.

24. Burns JM, Davenport TA, Durkin LA, Luscombe GM, Hickie IB. The internet as a setting for mental health service utilisation by young people. Med J Aust. 2010;192(Suppl 11):S22-S26.

25. Medibank Health Solutions; Nous Group. The Case for Mental Health Reform in Australia: A Review of Expenditure and System Design. Wellington, NZ: Medibank Health Solutions and Nous Group; 2013. Available from: https://www.medibank.com.au/Client/Documents/Pdfs/ The_Case_for_Mental_Health_Reform_in_Australia.pdf. Accessed April 24, 2014.

26. Gould MS, Munfakh JL, Lubell K, Kleinman M, Parker S. Seeking help from the internet during adolescence. J Am Acad Child Adolesc Psychiatry. 2002;41(10):1182-1189.

27. Suzuki LK, Calzo JP. The search for peer advice in cyberspace: An examination of online teen bulletin boards about health and sexuality. J Appl Dev Psychol. 2004;25(6):685-698.

28. Spittaels H, De Bourdeaudhuij I. Implementation of an online tailored physical activity intervention for adults in Belgium. Health Promot Int 2006;21(4):311-319

29. Santor DA, Poulin C, LeBlanc JC, Kusumakar V. Online health promotion, early identification of difficulties, and help seeking in young people. J Am Acad Child Adolesc Psychiatry. 2007;46(1): 50-59.

30. Oh E, Jorm AF, Wright A. Perceived helpfulness of websites for mental health information: a national survey of young Australians. Soc Psychiatry Psychiatr Epidemiol. 2009;44(4):293-299.

31. Burke M, Marlow C, Lento T. Social Network Activity and Social WellBeing: CHI '10 Proceedings of the SIGCHI Conference on Human Factors in Computing Systems, Atlanta, Georgia, USA, April 10-15, 2010. New York, NY, USA: Association for Computing Machinery; 2010.

32. McGorry PD. The specialist youth mental health model: strengthening the weakest link in the public mental health system. Med J Aust. 2007;187(Suppl 7):S53-S56.

33. Berger M, Wagner TH, Baker LC. Internet use and stigmatized illness. Soc Sci Med. 2005;61(8):1821-1827.

34. Ellis LA, Collin P, Hurley PJ, Davenport TA, Burns JM, Hickie IB Young men's attitudes and behaviour in relation to mental health and technology: implications for the development of online mental health services. BMC Psychiatry. 2013;13:119.

35. Collin PJ, Metcalf AT, Stephens-Reicher JC, et al. ReachOut. com: The role of an online service for promoting help-seeking in young people. Advances in Mental Health. 2011;10(1):39-51.

36. Wright A, Jorm AF, Harris MG, McGorry PD. What's in a name? Is accurate recognition and labelling of mental disorders by young people associated with better help-seeking and treatment preferences? Soc Psychiatry Psychiatr Epidemiol. 2007;42(3):244-250.

37. Collin P, Rahilly K, Stephens-Reicher J, Blanchard M, Herrman H, Burns J. Complex Connections: Meaningful Youth Participation for Mental Health Promotion. Proceedings of Interrupting Transmission: Youth / Change / Policy / Practice. National Youth Sector Conference; Darling Harbour, Australia, May 30-June 1, 2011. Surry Hills, New South Wales: Australian Youth Affairs Coalition, 2011.

38. Farthing R. Why Youth Participation? Some Justifications and Critiques of Youth Participation Using New Labour's Youth Policies as a Case Study. Youth and Policy. 2012;109:71-97.

39. Biedrzycki K, Lawless AP. The Headroom Model: A Conceptual and Practical Description. Bedford Park, South Australia: Flinders University of South Australia; 2009. Available from: http://dspace2.flinders. edu.au/xmlui/bitstream/handle/2328/25231/Headroom\%20report. pdf? sequence=1. Accessed April 23, 2014.

40. World Health Organization. Ottawa Charter for Health Promotion. First International Conference on Health Promotion. Ottawa, Canada, November 17-21, 1986. Available from: http://www.euro.who.int/_ data/assets/pdf_file/0004/129532/Ottawa_Charter.pdf?ua=1. Accessed April 28, 2014.
41. World Health Organization. WHOQOL Measuring Quality of Life. Geneva: World Health Organization; 1997. Available from: http://www. who.int/mental health/media/68.pdf. Accessed April 28, 2014.

42. Victorian Health Promotion Foundation. A Plan for Action 2005-2007: Promoting Mental Health and Wellbeing. Carlton, Victoria, Australia; 2005. Available from: http://www.vichealth.vic.gov.au/ /media/ ResourceCentre/PublicationsandResources/General/VH\%20action\%20 plan-web.ashx. Accessed April 28, 2014.

43. ABS.gov.au [homepage on the Internet]. Causes of Death 2010 Australian Bureau of Statistics; 2010; [update March 14, 2013]. Available from: http://www.abs.gov.au/AUSSTATS/abs@.nsf/ Lookup/3303.0Explanatory\%20Notes12010?OpenDocument. Accessed April 23, 2014.

44. Herrman H, Saxena S, Moodie R, editors. Promoting Mental Health: Concepts, Emerging Evidence, Practice. Geneva: World Health Organization; 2005. Available from: http://www.who.int/mental_health/ evidence/MH_Promotion_Book.pdf. Accessed July 13, 2011.

45. Baum FE, Bush RA, Modra CC, et al. Epidemiology of participation: an Australian community study. $J$ Epidemiol Community Health. 2000;54(6):414-423.

46. Walker L, Verins I, Moodie R, Webster K. Responding to the Social and Economic Determinants of Mental Health: A Conceptual Framework for Action. In: Herrman H, Shekhar S, Moodie R, editors. Promoting Mental Health. Concepts, Emerging Evidence, Practice. Geneva: World Health Organization; 2005:89-106.

47. Victorian Health Promotion Foundation. Social Inclusion as a Determinant of Mental Health and Wellbeing. Carlton, Victoria, Australia: Victorian Health Promotion Foundation; 2005. Available from: http://www.vichealth.vic.gov.au/ /media/ProgramsandProjects/ Publications/Attachments/Social_Inclusion_Final_Fact_sheet.ashx. Accessed May 15, 2014.

48. Burns J, Boucher S, Glover S, et al. Preventing Depression in Young People. What Does the Evidence Tell Us and How Can We Use it to Inform School-Based Mental Health Initiatives? Adv Sch Ment Health Promot. 2008;1(2):5-16.

49. Glover S, Burns J, Butler H, Patton G. Social environments and the emotional wellbeing of young people. Family Matters. 1998; 49(Autumn):11-16.

50. World Health Organization. Social Determinants of Health: The Solid Facts. 2nd ed. Copenhagen: World Health Organization; 2003. Available from: http://www.euro.who.int/_data/assets/pdf_file/0005/98438/ e81384.pdf. Accessed May 15, 2014.

51. White R, Wyn J. Youth and Society: Exploring The Social Dynamics of Youth Experience. 2nd ed. Melbourne, Australia: Oxford University Press; 2008.

52. Collin P. Policies for Youth Participation and the Development of New Political Identities: Proceedings of are We there Yet? National Youth Affairs Conference; Melbourne, Victoria, Australia; 2007. Available from: http://www.yacvic.org.au/component/docman/ doc_download/122-are-we-there-yet-conference-proceedings-peerreviewed-papers?Itemid $=$. Accessed August 21, 201

53. Bell J, Vromen A, Collin P. Rewriting the Rules for Youth Participation: Inclusion and Diversity in Government and Community Decision Making. Canberra, Australia: National Youth Affairs Research Scheme; 2008. Available from: http://www.uws.edu.au/_data/assets/ pdf_file/0009/476343/rewriting_the_rules_for_youth_participation.pdf. Accessed April 28, 2014.

54. Vromen A, Collin P. Everyday and informal youth participation: comparing views and practices of Australian policy practitioners with young people from diverse backgrounds. Young: Nordic Journal of Youth Research. 2010;18:97-112.

55. Swanton R, Collin P, Burns J, Sorensen I. Engaging, Understanding and Including Young People in the Provision of Mental Health Services. Int J Adolesc Med Health. 2007;19(3):325-332.

56. Collin P. The internet, youth participation policies, and the development of young people's political identities in Australia. Journal of Youth Studies. 2008;11(5):527-542. 
57. Wierenga A, Wood A, Trenbath G, Kelly J, Vidakovic O. Sharing a New Story: Young People in Decision-Making. Melbourne: Foundation for Young Australians, Australian Youth Centre, University of Melbourne, Australia; 2003. Available from: http://web.education.unimelb.edu.au/ yrc/linked_documents/WP23.pdf. Accessed April 24, 2014.

58. Blanchard M, Metcalf A, Burns J. Bridging the Digital Divide: Young People's Perspectives on Taking Action. Sydney, Australia: Inspire Foundation, Orygen Youth Health Research Centre; 2008. Available from: http://unpan1.un.org/intradoc/groups/public/documents/apcity/ unpan036072.pdf. Accessed April 30, 2014.

59. Harris A, Wyn J, Younes S. Beyond apathetic or activist youth: 'Ordinary' young people and contemporary forms of participation. Young: Nordic Journal of Youth Research. 2010;18(1):9-32.

60. Kirby P, Lanyon C, Cronin K, Sinclair R. Building a Culture of Participation: Involving Children and Young People in Policy, Service Planning, Development and Evaluation: Research Report. Nottingham, UK: Department for Education and Skills Publications; 2003. Available from: http://www.gyerekesely.hu/childpoverty/docs/ involving_children_report.pdf. Accessed April 28, 2014.

61. Sinclair R. Participation in practice: making it meaningful, effective and sustainable. Children and Society. 2004;18(2):106-118.

62. Kirby P, Bryson S. Measuring the Magic? Evaluating and Researching Young People's Participation in Public Decision Making. London, UK: Carnegie Young People Intiative; 2002. Available from: http://www. participationworks.org.uk/files/webfm/files/resources/k-items/carnegie/ Measure\%20the\%20Magic.pdf. Accessed April 28, 2014.

63. Kessler RC, Andrews G, Colpe LJ, et al. Short screening scales to monitor population prevalence and trends in non-specific psychological distress. Psychol Med. 2002;32(6):959-976.

64. Berry HL, Rodgers B, Dear KB. Preliminary development and validation of an Australian community participation questionnaire: types of participation and associations with distress in a coastal community. Soc Sci Med. 2007;64(8):1719-1737.

65. Vromen A. 'People try to put us down ...': Participatory Citizenship of 'Generation X'. Aust J Polit Sci. 2003;38(1):79-99.

66. Burns J, Morey C, Lagelée A, Mackenzie A, Nicholas J. Reach Out! Innovation in service delivery. Med J Aust. 2007;187(Suppl 7): S31-S34.

67. James AM. Principles of youth participation in mental health services. Med J Aust. 2007;187(Suppl 7):S57-S60.

68. Australian Youth Affairs Coalition. Submission to the Joint Select Committee on Cyber-Safety Issues Affecting Children and Young People. Melbourne, Victoria, Australia: Australian Youth Affairs Coalition; 2010. Available from: http://www.privacy.vic.gov.au/privacy/web2.nsf/files/ cyber-safety-issues-affecting-children-and-young-people-2010/\$file/ submission_06_10_no2.pdf. Accessed April 28, 2014.

69. Collin P. The Making of Good Citizens: Participation Policies, the Internet and Youth Political Identities in Australia and the United Kingdom. [doctoral thesis]. Sidney, Australia: Univesity of Sydney; 2009.

70. Nicholas J. The role of internet technology and social branding in improving the mental health and wellbeing of young people. Perspect Public Health. 2010;130(2):86-90.
71. Webb M, Burns J, Collin P. Providing online support for young people with mental health difficulties: challenges and opportunities explored. Early Interv Psychiatry. 2008;2(2):108-113.

72. Kauer SD, Mangan C, Sanci L. Do online mental health services improve help-seeking for young people? A systematic review. J Med Internet Res. 2014;16(3):e66.

73. ReachOut.com by Inspire Foundation [homepage on the Internet]. About the Youth Ambassador program. ReachOut.com by Inspire Foundation; 2014. Available from: http://au.reachout.com/About-theYouth-Ambassador-Program. Accessed April 24, 2014.

74. Livingstone S, Helsper E. Balancing opportunities and risks in teenagers' use of the internet: The role of online skills and internet self-efficacy. New Media and Society. 2010;12(2):309-329.

75. McGorry PD, Tanti C, Stokes R, et al. headspace: Australia's National Youth Mental Health Foundation - where young minds come first. Med J Aust. 2007;187(Suppl 7):S68-S70.

76. Muir K, Powell A, Patulny R, et al. Headspace Evaluation Report. Social Policy Research Centre, University of New South Wales, Sydney, Australia; 2009.

77. Jorm AF. Australian young people's awareness of headspace, beyondblue and other mental health organizations. Australas Psychiatry. 2009; 17(6):472-474.

78. Scott EM, Hermens DF, Naismith SL, et al. Thoughts of death or suicidal ideation are common in young people aged 12 to 30 years presenting for mental health care. BMC Psychiatry. 2012;12:234.

79. Pro Bono Australia. Establishment of Orygen Youth Health Research Centre. Windsor, Victoria, Australia: Pro Bono Australia; 2013. Available from: http://www.probonoaustralia.com.au/top-50-philanthropic-gifts/ node/241. Accessed April 24, 2014.

80. McGorry P, Bates T, Birchwood M. Designing youth mental health services for the 21st century: examples from Australia, Ireland and the UK. Br J Psychiatry Suppl. 2013;54:s30-s35.

81. McGorry PD, Nelson B, Goldstone S, Yung AR. Clinical staging: a heuristic and practical strategy for new research and better health and social outcomes for psychotic and related mood disorders. Can J Psychiatry. 2010;55(8):486-497.

82. Monson K, Thurley M. Consumer participation in a youth mental health service. Early Interv Psychiatry. 2011;5(4):381-388.

83. Orygen Youth Health. What do we do? Orygen Youth Health; 2014. Available from: http://oyh.org.au/oyh-clients/platform-team/what-dowe-do. Accessed April 23, 2014.

84. Orygen Youth Health. Meetings. Orygen Youth Health; 2014. Available from: http://oyh.org.au/oyh-clients/platform-team/meetings. Accessed May 1, 2014.

85. ReachOut.com by Inspire Foundation. 2013 ReachOut.com Annual User Survey Results. Sydney: ReachOut.com by Inspire Foundation; 2014. Available from: http://inspire.org.au/wp-content/uploads/2014/07/2013ReachOut.com-Annual-User-Survey.pdf. Accessed August 22, 2014.

86. Rickwood DJ. Promoting youth mental health: priorities for policy from an Australian perspective. Early Interv Psychiatry. 2011;5 Suppl 1:40-45.
Psychology Research and Behavior Management

\section{Publish your work in this journal}

Psychology Research and Behavior Management is an international, peerreviewed, open access journal focusing on the science of psychology and its application in behavior management to develop improved outcomes in the clinical, educational, sports and business arenas. Specific topics covered include: Neuroscience, memory \& decision making; Behavior

\section{Dovepress}

modification \& management; Clinical applications; Business \& sports performance management; Social and developmental studies; Animal studies. The manuscript management system is completely online and includes a quick and fair peer-review system. Visit http://www.dovepress. com/testimonials.php to read real quotes from published authors. 